\title{
Therapeutic Effects of Multisensory Yoga Program on Mood, Initiation of Needs and Social Skills $f$ or Children with Autism Spectrum Disorder
}

\author{
Lyn G Litchke*, Ting Liu and Michaela Scroggins \\ Department of Health and Human Performance, Texas State University, USA
}

Submission: May 14, 2018; Published: June 19, 2018

*Corresponding author: Lyn Litchke, Department of Health and Human Performance, Texas State University-San Marcos, San Marcos, Texas, 78666, USA, Tel: 512-245-2951; Fax: 512-245-8678; Email: LL24@txstate.edu

\begin{abstract}
This study examined the therapeutic effects of a novel multisensory yoga program, called Kid Yoga Rocks (KYR), on five boys (5-7 years) with Autism Spectrum Disorder (ASD). KYR was a 45min yoga program provided to children twice a week for four weeks. Each of the eight yoga sessions were videotaped and contained 31 yoga poses accompanied by multisensory equipment, chants, and songs. Children were tested before and after the eight yoga sessions on Yoga Pose Performance Assessment (YPPA), Treatment and Research Institute for Autism Spectrum Disorders Social Skills Assessment Problem Behavior Rating Scale (TSSAPBRS), and the Sparks Target Behavior Checklist. Observed changes were also documented daily utilizing a Modified Facial Mood Scale and a comprehensive narrative note. A significant increase from pretest to posttest was found $(\mathrm{t}(4)=-4.245, \mathrm{p}=0.013)$ indicating yoga training elicited higher imitation performance scores in YPPA subscales. A significant improvement was also found from pretest to posttest on sun salutation series $(\mathrm{t}(4)=-3.038, \mathrm{p}=0.038)$, balance series $(\mathrm{t}(4)=-8.5, \mathrm{p}=0.001)$, relaxation series $(t(4)=-2.814, p=0.048)$, and total percent change $(t(4)=-4.245, p=0.013)$. All children were classified in the mild problematic behavior category in TSSAPBRS. Thematic analysis identified four key factors associated with the yoga experience: (a) increased initiation of needs, (b) increased time on task, (c) positive environmental mood, and (d) leadership skills and relationship building.
\end{abstract}

Conclusion: In conclusion, the KYR program was effective in treating problematic behavior, mood, initiation of needs and social skills for these young male children with ASD.

Keywords: Autism; Multi-sensory yoga; Mood; Behavior; Initiation

\section{Introduction}

There are more than two million Americans that are affected by Autism Spectrum Disorder (ASD) and 10 million worldwide. According to the U.S. Centers for Disease Control and Prevention [1], 1 in 88 children in America have ASD, meaning there is a new diagnosis every $20 \mathrm{~min}$. Yearly, this rate is increasing 10 to 17 percent affecting more children and families [2]. ASD is characterized by symptoms including repetitive, stereo typical body movements, and deficits in social and communication skills which often produce problematic behaviors (e.g., tantrums, outbursts, impulsivity, aggression, and non-compliance ) that impede a child's ability to adjust to family life and school activities $[2,3]$. Currently, only $5 \%$ of research funds are dedicated to ASD [3], therefore, it is important to develop effective therapeutic training program so that the overall quality of life of these children can be improved.

One effective therapy that offers a unique treatment benefit for children with ASD's social, emotional, and behavioral deficits is yoga [4-6]. Yoga is listed as one of the top ten healthy approaches for mind and body recognized by the National Center for Complementary and Alternative Medicine [7]. Yoga is an ancient Indian mind-body practice that involves calming breathing techniques, hydrostatic postures, and relaxation exercises that not only improve physical health and well-being, but also enhance emotional stability in children with ASD [8]. In general, yoga practiced 2-5 times 30 to 45 min sessions per week for 8-48 weeks has demonstrated overall improvements in lowering stress levels, stillness, prompting self-awareness, eye contact, better responses to verbal cues, emotion expression, and social interaction with children with ASD [4-6,9-13].

Yoga is a therapeutic program that has been reported in the literature pertaining to ASD. However, there have been no reports in the literature as to what approaches are utilized to best benefit the children with ASD in mood, social skills, imitation and physical functions. Thus, the purpose of this study was to explore the effects of a novel multisensory yoga program on mood, social skills, on-task and compliance behaviors, imitation, and physical function in children with ASD. 


\section{Methods}

\section{Participant}

Participants were recruited from a local autism summer camp. Five children (all males) between 5-7 years old with ASD participated in this study. Three children had a diagnosis of Asperger Syndrome and two were diagnosed with pervasive developmental disorder not otherwise specified (PDD-NOS). Participants' demographic data are presented in Table 1. Participating parents were informed of their rights and the nature of the task, and were asked to sign a consent form prior to their child's participation. The study was approved by the Institutional Review Board of the local University.

Table 1: Demographic information of participants' age, gender and disorder.

\begin{tabular}{|c|c|c|c|}
\hline Pseudonym & Gender & Age & Autism Spectrum Disorder \\
\hline Mark & M & 7 & Asperger Syndrome \\
\hline Tom & M & 7 & Asperger Syndrome \\
\hline Andrew & M & 6 & PDD-NOS \\
\hline Walter & M & 6 & Asperger Syndrome \\
\hline William & M & 7 & PDD-NOS \\
\hline
\end{tabular}

Note: M=Male; PDD-NOS=Pervasive Developmental Disorder Not Otherwise Specified.

\section{Procedure}

The multisensory yoga program called Kid Yoga Rocks (KYR) was provided as a part of the four-week camp for children with ASD twice a week and $45 \mathrm{~min}$ per session. All campers had a counselor assigned to work with them one on one throughout each yoga session and five therapeutic recreation (TR) graduate students assisted during each session. The counselor's role was to assist as necessary with the child's behavior and the yoga poses. The counselors were instructed to let each child attempt the pose first, follow with a verbal prompt to achieve a more accurate pose, and then finally physical assistance if warranted. The TR students' roles were to model poses, video record the session, document observations, and transcribe the data.

All eight yoga sessions were video recorded and five TR graduate student observers were trained by the primary investigator (PI) to complete all the instrument measures prior to administration. The TR observers were considered trained once the $90 \%$ inter-rater agreement was achieved between the PI and TR [14]. Pre and post testing was done on the first and last day of camp using four instruments.

\section{Instruments}

Yoga Pose Performance Assessment (YPPA) is designed to measure children's imitation skills and it's based on the Imitation Test Battery and Yoga Intervention Assessment of Radhakrishna [15]. YPPA has 31 yoga poses divided into six subsections. The subsections consist of: 1) seven breath and chanting poses, 2) six sun salutation poses, 3) five warrior poses, 4) five balance poses,
5) five flexibility poses, and 6) three relaxation poses. Each of the 31 poses is scored using an ordinal scale ranging from 0-5. For example, a score of zero is classified as never or refusing to do the pose at $0 \%$, whereas a score of five represents mastery of pose performance between $81-100 \%$. ${ }^{*}$ The total score is obtained by adding points from each of the six subsections and it ranges from $0-155$. The YPPA imitation score ranging from 0-38 indicates unsatisfactory performance; 39-77 indicates inconsistent performance, 78-116 effective performance, and 117-155 exceptional performance rating.

Two instruments were used to measure social behavior outcomes: the TSSA Problem Behavior Rating Scale (TSSAPBRS; [16] and Sparks Target Behavior Checklist (STBC). The TSSAPBRS is a five-point Likert-type scale ranging from zero (behavior not at all problematic) through four (very problematic behavior). For example, the statements describe impulsive behavior, flapping of the hands, and hurting themselves or others. There are a total of 18 behaviors with a possible score ranging from 0 to 72 . A total score of 0 represents no behavior problems, 1-24 is mild behavior problems, 25-48 has moderate behavior problems, and 49-72 indicates severe behavior problems. The STBC is a nominal scale that embodied 59 relational behaviors in four main sections: (a) 16 staying on task related behaviors, (c) 13 motivation and coping behaviors, (d) 11 adult interactions, and (e) and19 peer interactions. The research observer checked behaviors that are appeared to be most interference with yoga performance.

Modified Facial Mood Scale (MFMS) was also used in this study. MFMS is based on the works of Cheng [17] and Khalsa [11] comprised of the following five emotions: bored, sad, frustrated, happy, and excited. Two real-life child faces of each mood accompanied by brief single word descriptions, and a number from one to five were displayed separately on large posters mounted on the yoga class wall. The participants were asked to select the picture and or word that best described how they were feeling at the beginning and end of each yoga session. The counselor would then record their response on the corresponding mood scale score sheet along with their observation of their camper's mood, and later the TR observer would record mood through the video. Each of the five emotions on the score sheet was labeled from was one to five for later data analysis. A final measurement was the completion of a comprehensive narrative progress report by the TR observers. They were required to summarize their assigned child's overall physical, cognitive, social, communication, behavioral, and emotional performance during the yoga sessions.

\section{Intervention}

KYR was designed by the PI, who was a certified Lakshmi Voelker Chair Yoga Teacher (Get Fit Where You Sit, 2010), a Level One and Yoga Fit Kids Instructor (Torrence, CA), and a Certified Therapeutic Recreation Specialist (National Counsel for Therapeutic Recreation Certification, New York, NY). The PI 
trained one of the TR students, who was also a certified yoga group fitness instructor, to lead the yoga class.

KYR was developed to specifically target age appropriate social and communication skills, specific characteristics, and behavior issues for children with ASD* such as expressing their feelings correctly, remaining on the required task, engaging with peers, and maintain a calm demeanor [4]. Particularly, the $45 \mathrm{~min}$ multisensory KYR yoga routine includes 31 total poses: such as specific chanting and familiar children's songs for language enrichment; breathing exercises for emotional and behavior coping skills; hatha yoga postures accompanied by animal sounds and counting for imitation and physical skill development; individual yoga bins containing animal bean bag, pinwheel, feather, miniature flashlight, towel, a 3 ringed yoga binder consisting of colored pictures of a child doing each pose with written instructions for cognitive and sensory stimuli; and relaxation and positive affirmations for enhancement of body and self-awareness. The KYR yoga routine was done with mats positioned in a semi-circle, accompanied by soft relaxing music, and consisted of the following series: $5 \mathrm{~min}$ readiness with feeling identification, $7 \mathrm{~min}$ of chanting and breath work, $7 \mathrm{~min}$ sun salutation, $7 \mathrm{~min}$ warrior series, $7 \mathrm{~min}$ of balance training, $7 \mathrm{~min}$ of flexibility, and 5 final relaxation and positive affirmations. Yoga pose samples, instructions, benefits, equipment and cues are presented in Table 2.

Table 2: Yoga pose samples and benefits.

\begin{tabular}{|c|c|c|c|}
\hline Yoga Poses & Description and Instructions & Benefits & Props and Cues \\
\hline \multicolumn{4}{|c|}{ Chanting and Breath Series } \\
\hline $\begin{array}{l}\text { Pinwheel } \\
\text { breath work }\end{array}$ & $\begin{array}{l}\text { The participants were asked: "Grab the pinwheel out of } \\
\text { your bin; inhale through the nose and on the exhale blow } \\
\text { on the pinwheel" (repeat x3) }\end{array}$ & $\begin{array}{l}\text { Promotes calmness; stilling the } \\
\text { mind; adding the prop promotes } \\
\text { engagement and focus }\end{array}$ & 18" pinwheel \\
\hline Lions Breath & $\begin{array}{l}\text { From a kneeling position:"inhale through the nose raising } \\
\text { up high on your knees with your hands raised like lions } \\
\text { paws; exhale and roar like a lion while sticking your } \\
\text { tongue out. Lower back down to your knees and place } \\
\text { their hands back on the ground" (repeat x3) }\end{array}$ & $\begin{array}{l}\text { Reduces stress, mild depression, } \\
\text { and anxiety }\end{array}$ & “ROAR like a LION!” \\
\hline Super brain & $\begin{array}{l}\text { The participants were verbally cued as follows: "stand } \\
\text { with your feet hip distance apart and cross your arms } \\
\text { over your chest; pinch your ear lobes with thumb on } \\
\text { the front and index finger on the back. Next, place your } \\
\text { tongue on the roof of your mouth and inhale through the } \\
\text { nose while standing and exhale while squatting down; } \\
\text { inhale on the way up back up to stand" (repeat x5) }\end{array}$ & $\begin{array}{l}\text { Allows relaxation, concentration, } \\
\text { and alters mood; relieves } \\
\text { anxiety, reduces stress, enhances } \\
\text { creativity, energizes brain } \\
\text { activity; increases inner peace, } \\
\text { psychological stability }\end{array}$ & \\
\hline \multicolumn{4}{|c|}{ Balance Series } \\
\hline Airplane & $\begin{array}{l}\text { The participants were guided: "bend at the hips and bring } \\
\text { one leg back perpendicular to the floor. Place your arms } \\
\text { straight out to the side horizontally. Repeat on other side" }\end{array}$ & $\begin{array}{l}\text { Improves balance, develops } \\
\text { concentration, and strengthens } \\
\text { legs, chest, and arms }\end{array}$ & $\begin{array}{l}\text { Sing while holding pose: "fly } \\
\text { like airplane, fly like airplane, } \\
\text { fly like an airplane in the } \\
\text { sky; again on the other side } \\
\text { (repeat song) }\end{array}$ \\
\hline \multicolumn{4}{|c|}{ Flexibility Series } \\
\hline Table & $\begin{array}{l}\text { The participants are asked: "Get your beanbag toy out } \\
\text { of the bin. Lay down on your back. Place the toy on your } \\
\text { stomach to aid with balance. Then, inhale, while raising } \\
\text { up on your hands with hips in the air. Then, exhale and } \\
\text { slowly lower bodies back to mat (repeat x3) }\end{array}$ & $\begin{array}{l}\text { Stretches pelvis, chest; and } \\
\text { shoulders; aligns spine, } \\
\text { strengthens bones; increases } \\
\text { coordination and balance }\end{array}$ & Animal beanbag toy \\
\hline
\end{tabular}

\section{Data Analysis}

Descriptive data were used to describe the children (M=6.6 years) with ASD's YPPA and TSSAPBRS performance. Paired samples t-tests were conducted on YPPA and TSSAPBRS total scores to compare yoga pose imitation and problematic behavior of children with ASD before and after the eight yoga training sessions. The six YPPA subscales (i.e., breath, sun salutation, warrior, balance, flexibility, and relaxation) were also compared to assess mastery of each yoga pose. Results were considered significant at p-values of less than 0.05 .

The qualitative data analysis was captured from the STBC, MFMS, and narrative progress notes and focused on identifying and interpreting the outcomes of KYR intervention [18]. First, all five of the TR student observers were instructed to document, in the form of a narrative note, the outcomes of each session using both objective data and meaningful subjective quotes in relation to the participants' level of function cognitively, physically, socially, emotionally, and behaviorally. The 36 completed narrative notes were imported by the PI and the KYR lead TR student observer directly into a spreadsheet and each response was placed in a separate column, organized under the five areas of function. Second, the STBC data from the pre and post score sheet was transposed into a spread sheet where $0=$ unobserved behavior and the $\mathrm{X}$ marked on the original score sheet was converted to a $1=$ observed behavior. The data were 
then colored coded as follows: 0 before and after were coded green=no observed problem; 1 before and 1 after were coded yellow=behavior remained same; 1 before and 0 after were coded blue=behavior improved; and 0 before and 1 after were coded red=behavior worsened. For each participant, a total score was recorded for behaviors that remained the same, worse, or better. An overall, total score for all five participants for each of the three areas were recorded to aide in the interpretation.

Third, the MFMS scores from before and after each yoga session were entered into a spread sheet for each participant as follows: 1 =bored, $2=$ sad, 3 =frustrated, 4=happy, 5=excited, and $\mathrm{N} / \mathrm{A}=$ missing data. Scores were reported for participant, counselor, and TR student observer. The analysis proceeded in several steps using a constant comparison method to generate initial codes and refine the codes to interpret the themes emerging from the data and ensure scientific rigor in qualitative research [18]. First, the PI and the lead TR student open coding and reading participant's narrative notes, STBC and MFMS data independently to form initial analytical hunches about categorizing the data that had relevance to the yoga program. Second, the PI and the lead TR compared the preliminary ideas, collaboratively identified and defined the initial codes with $100 \%$ agreement and then formed an initial code key. The PI used this initial code key on the other four participants'28 other narrative notes, STBC, and MFMS adding or merging codes as needed using a constant-comparative method in which pieces of data were compared and categorized together if they were similar or used to form a new category if the piece of data was unique [18]. This approach resulted in an additional reorganization of the 16 initial codes that were approved by both the PI and TR and a final code key of six was produced. The PI and TR student then used the final code key to re-code all five participants' narrative data, STBC, and MFMS data, and refined the names of any codes that emerged to adequately capture the themes [19].

\section{Trustworthiness}

Methodological triangulation was achieved via use of multiple data sources to test for consistency in the findings [20]. The depth of triangulated data revealed the complexity of participant's yoga experiences, brought plausibility to essential themes, and established authenticity of findings [20]. This authenticity was further supported through data saturation whereby repetition of information and confirmation of previously collected data across residents occurred. The themes were reviewed and verified during a replication of the four-week, eight sessions of yoga KYR program with the same participants one year later at the same camp by five additional TR graduate student observers. Finally, each theme was supported by the words and actions of participants' initially and subsequently post replications.

Consistent with qualitative methods of reporting researcher's relationship to data [20], the PI possessed 31 years as a CTRS, 20 years' experience working with ASD, and three years utilizing yoga for children with ASD. The five TR student observers had 18 months of TR graduate course work and one semester working with children who have ASD.

\section{Results}

Descriptive statistics showed that $40 \%$ of the children with ASD categorized as unsatisfactory imitation performance on YPPA before the yoga training. However, only $20 \%$ of the children were in the unsatisfactory performance category after the training. All children were in the mild problematic behavior category in TSSAPBRS.

A paired sample t-test was calculated to compare the pretest YPPA total scores to the posttest scores. The mean on the pretest was $65(\mathrm{SD}=33.66)$ and the mean of the posttest was 92.4 $(\mathrm{SD}=39.25)$. A significant increase from pretest to posttest was found $(\mathrm{t}(4)=-4.245, \mathrm{p}=0.013)$ indicating yoga training elicited higher imitation performance scores (Figure 1). No significant problematic behavior difference from pretest to post test was found $(\mathrm{t}(4)=0.684, \mathrm{p}>0.05)$.

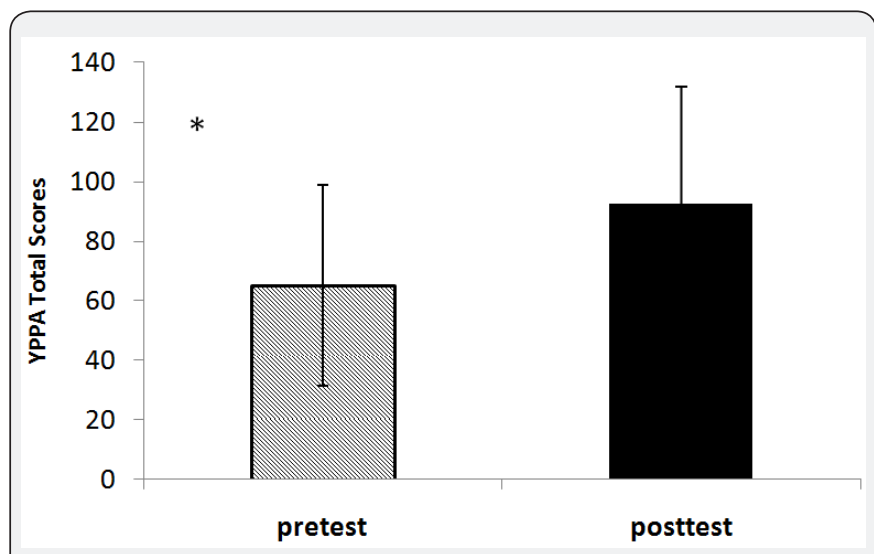

Figure 1: Significant improvement in pose imitation performance before and after the yoga training.

*indicates significant differences

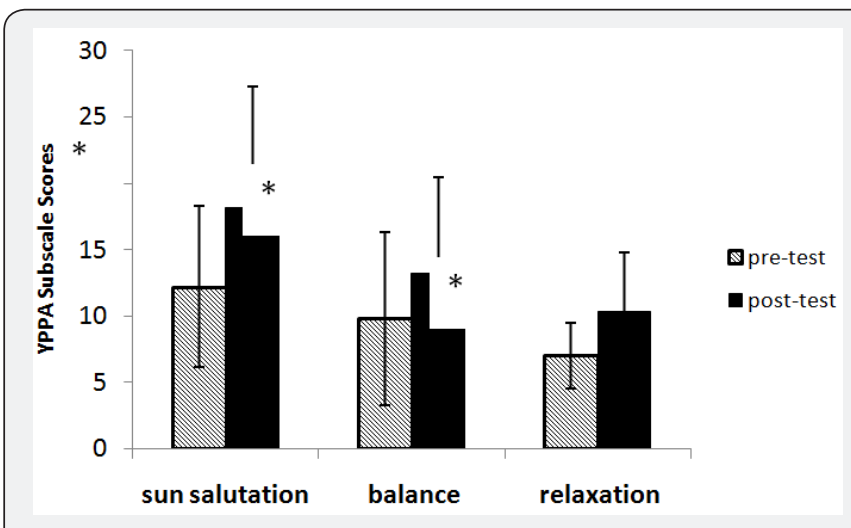

Figure 2: Significant improvement in imitation performance on sun salutation, balance, and relaxation before and after the yoga training.

*indicates significant differences

The paired samples t-tests were also used to assess six YPPA subscales. A significant improvement was found from pretest to posttest on sun salutation series $(\mathrm{t}(4)=-3.038, \mathrm{p}=0.038)$, balance 
series $(t(4)=-8.5, p=.001)$, relaxation series $(t(4)=-2.814$, $\mathrm{p}=0.048)$, and total percent change $(\mathrm{t}(4)=-4.245, \mathrm{p}=0.013)$. These results suggested that children with ASD benefited from using yoga training in three poses imitation series performance (Figure 2).

Thematic analysis identified four key factors associated with our novel multisensory yoga program KYR: (a) increased initiation of needs, (b) increased time on task, (c) positive environmental mood, and (d) leadership skills and relationship building. The themes are outlined below with representative data from the STBC, MFMS, narrative notes with representative quotes.

\section{Initiation of needs}

Over the course of the 4-week, four out of five participants progressed in their ability to appropriately express their needs for assistance with pose mastery and personal desires. For example, Tom, a 7 year old, made the largest transition from inappropriate ways of expressing his feeling, refusing assistance with the poses, and the lack of participation and attention with the yoga series; to reaching out physically to his college counselor to stabilize himself during a balance pose, asking for assistance, self-initiating looking at his binder to model the pose, hearing the name of the pose, and from recall doing the pose, to finally assisting the leader in the last two session to lead the yoga class. In addition, one of Tom's counselor in yoga (who was also his school behavior therapist) and Tom's parent noted improvement in his ability to calm himself through use of lions breath and superbrain yoga poses throughout the rest of the day at camp, in the car, and at home. In addition, Andrew, six years of age, began creating his own poses, or moving into mouse (child's pose) outside the pose sequence, to finally coming forward to the PI prior to class and tapping her saying "I don't like yoga", and" I want to move faster." In addition, Mark, a 7 year old, would tug on his ears throughout various points in the class, similar to the superbrain pose when he needed to calm down.

\section{Time on task}

Increased time on task and pose mastery (especially balance poses of tree and stork) through use of songs and kid gear props were noted for Tom and Edward. According to the STBC and narrative note data, Tom and Edward showed a shift from distraction to increased ability to follow directions when the pose was accompanied by a prop, song, animal sound, affirmation during relaxation, or a chant. Overall, the STBC confirmed 19 improvements in the "on task" sub-category for everyone except Mark.

\section{Positive environmental mood}

Based on the MFMS and the narrative notes, there appeared to be an overall sense of enjoyment of yoga, except for Andrew. Four of the five males showed no changes in mood before and after each session except for Walter who on several occasions went from $2=$ sad to happy=4; happy $=4$ to excited $=5$; and excited $=5$ to happy $=4$. Over the 4 weeks, Mark maintained a level of excitement; Tom and Edward were happy=4; while Andrew reported being bored $=1$. Compliance and attendance records indicated $100 \%$ positive environmental mood for Mark, Tom and Edward with Walter at $94 \%$ and Andrew at $75 \%$. From the narrative note data, Mark, Edward, and Tom smiled and laughed during the songs that accompanied the balance poses and chanting. Interestingly, Mark would show his excitement when he would enter the beginning of class announcing his arrival "I'm here. I'm here" At the end of his second yoga class, he asked his TR observer "Does Namaste mean Amen?" demonstrating a shift in insight on the spiritually calming environment of the KYR class.

\section{Leadership skills and relationship building}

Leadership skills and relationship building theme was derived from the narrative note data that described four of the five males who demonstrated a progressive improvement in relationship with their counselor. Further evidence from Tom and Mark showed that they responded to taking on a leadership role modeling the poses with their TR observer. For example, an excerpt from Walter's data revealed: "Initially withdrawn from group. Started to engage with his college counselor, and responds to verbal prompts to do poses. Starts to interact with counselor." Mark's notes from two separate classes stated that he engaged very well when he got to lead poses for the group. Finally, Tom led the last two yoga classes with the KYR instructor who was also his TR observer indicating the children improved their leadership skills and relationship building with 8-sesison of KYR.

\section{Discussion}

This study aimed to investigate the therapeutic effect of a multisensory yoga program for five young males with ASD. It provides a useful contribution to the literature in the field of alternative and complementary medicine approach to treatment options for children with ASD. In particular, TRs who are trained to employ a number of interventions when facilitating treatment for children with ASD may choose the multisensory approach to yoga based on the positive outcomes in this study. More specifically, results illustrated that the multisensory yoga training elicited higher imitation performance scores, and in turn improved the participants' mood, ability to stay on task, expression of their needs, and their capacity to form social relationships.

The quantitative findings showed a significant improvement in yoga performances for the sun salutation, balance, and relaxation series. These results are in line with the findings of Goldberg [9] and Kenny [10]. Specifically, Kenny [10] found a significant increase in balance and coordination for 24 children with ASD and related disorders through an integrated movement therapy yoga program. Goldberg [9] also found significant increase in the ability to follow more complex poses for six 
elementary aged children with ASD who engaged in eight weeks of yoga. In this study, all five participants improved in their skill level for the specific balance poses of tree and stork. Beyond the physical functions of yoga poses are the mental benefits. According to Kirk et al. [21], the mental benefits of the tree and stork balance poses are the calming of the mind and increasing in concentration and focus. Our participants also increased significantly in performing the sun salutation poses cat/cow, downward facing dog, and frog. The mental benefits of these poses can be energizing the mind, increasing focus, and reducing stress and anxiety [21]. In addition, four of the five males boys increased their capacity to lay quietly covered in a towel during ragdoll, and all five improved in their ability to repeat the lyrical self-affirmation poem during relaxation poses at the end of class.

The qualitative findings revealed an increased ability for our participants not only to achieve pose mastery, but also stay on task and express their needs to calm themselves. In congruence with the our results, Kenny [10] found improvements in participants ability to follow along with the yoga activities and stay on task with the poses which lead to less disruptive behaviors. One of the main goals of Kenny's yoga program was to promote self-calming. A pose worth particular mention is superbrain. Superbrain showed improvement in four of our five participants. Tom, Mark, Walter and Edward appeared to use this pose during class at various times throughout the rest of the day at camp to calm themselves down. Koterba [13] studied the effects of superbrain on children with ASD and ADHD and found an overall calming effect as well as significant changes in ability to focus and pay attention which carried over in school and at home. Our study participant Tom transitioned from exhibiting many disruptive behaviors to being able to self-initiate the use of two poses throughout the rest of the day in camp, in the car, and on the way home to calm himself. In general, it has been reported that children with ASD showed less problematic and disruptive behaviors in the classroom as a result of yoga participation $[6,12]$ which is line with our findings.

One of the most significant and powerful aspects of KYR program was the use of yoga gear props, songs, and sounds. Other researchers incorporated variety multisensory additions to their yoga program and found it's beneficial when working with children with ASD [6,9,10]. For example, Goldberg incorporated music, visual aids and stories, Kenny enriched yoga with language, social interaction and self-esteem building, and Rosenblatt added music and dance. In our KYR program, the significant changes in pose mastery and imitation were found in the sun salutation, balance, and relaxation series. Our sun salutation poses were all accompanied by animal sounds. Our balance poses were performed with familiar kid songs and counting to 10 . The relaxation with soft music, a lyrical self-affirmation poem where each line was repeated and accompanied by a miniature flash light representing the light in their heart from the line in the poem.
Another important finding from this research is the overall enjoyment and compliance with the yoga program. Four of the five participants' mood was happy or excited throughout the 4 weeks of KYR yoga program. Andrew who was bored initially was able to express his need in an appropriate manner for more movement. Future therapists and practitioners should include children's enjoyment and compliance designing future KYR programs. Radhakrishna et al. [22] found that the six participants with ASD began to greet their therapist/buddy at the beginning of class with a smile and come closer to them. Our participants, Tom and Mark, even took on class leadership roles during the last two sessions standing with their counselors on their mat and aiding in instruction of poses and modeling. These findings validate the social aspect of relationships were formed during KYR between the participants and their college counselor and TR student observer [23].

\section{Limitations and Future Research}

There are several limitations that warrant caution when interpreting the findings. One limitation of this study is that the small sample size and short duration of the therapeutic yoga program. It is possible that additional themes would have arisen with larger sample size. This study is further limited by the narrow age range with male participants and lack of control group. Perhaps the quantitative findings would have been more revealing had the study contained some female participants and a control group. Future research can greatly enhance our understanding of the use of therapeutic yoga interventions by including large samples, more females, and a control group, with specific multisensory yoga protocol for children with ASD.

\section{Conclusion and Future Implications}

The significance of the quantitative findings is subtle yet appears to be in congruence with the qualitative themes gleaned from the study data. This study has several significant implications for therapists and health care practitioners working with children with ASD. Primarily, the results indicate that a multisensory yoga intervention program is feasible, inexpensive, and beneficial for children with ASD. Our findings showed that yoga was enjoyable, fulfilling, and socially rewarding. This implication suggests that children with ASD tend to be more complied in school and at home after yoga participation. Our results also highlight the need for alternative and complementary forms of yoga programs, specifically aimed at meeting the needs of children with ASD. In conclusion, the KYR therapeutic yoga program showed efficacy in treating problematic behavior, mood, initiation of needs, and social skills for these young male children with ASD. A large scale study is needed in the future to address the potential carry-over effects of yoga program on children with ASD's behaviors in school, home and community.

\section{References}

1. Centers for Disease Control and Prevention (2013) CDC Features - New data on autism spectrum disorders. 
2. See CM (2012) The use of music and movement therapy to modify behavior of children with autism. Journal of Social Science \& Humanities 20(4): 1105-1116.

3. Autism Speaks (2013) What is autism?

4. Ehleringer J (2010) Yoga for children on the autism spectrum. International Journal of Yoga Therapy 20: 131-139.

5. Peck HL, Kehle TJ, Bray MA, Theodore LA (2005) Yoga as an intervention for children with attention problems. School Psychology Review 34(3): 415-424.

6. Rosenblatt LE, Gorantla S, Torres JA, Yarmush RS, Rao S, et al. (2011) Relaxation response-based yoga improves functioning in young children with autism: A pilot study. J Altern Complement Med 17(11) 1029-1035.

7. National Center for Complementary and Alternative Medicine (NCCAM, 2011) Yoga for health: An introduction.

8. Davis J (2009) On yoga therapy \& autism. Yoga Therapy Today, pp. 2326.

9. Goldberg L (2004) Creative relaxation SM: A yoga-based program for regular and exceptional student education. International Journal of Yoga Therapy 14: 68-78.

10. Kenny M (2002) Integrated movement therapy: Yoga-based therapy as a viable and effective intervention for autism spectrum and related disorders. International Journal of Yoga Therapy 12: 71.

11. Khalsa SB, Hickey Schultz L, Cohen D, Steiner N, Cope S (2012) Evaluation of the mental health benefits of yoga in a secondary school: A preliminary randomized controlled trial. J Behav Health Serv Res 39(1): 80-90.

12. Koenig K, Buckley Reen A, Garg S (2012) Efficacy of the get ready to learn program among children with autism spectrum disorders: A pretest-posttest control group design. Am J Occup Ther 66(5): 538546.

13. Koterba R (2007) Superbrain yoga in children with autism and ADHD Northern New Jersey, The Center for Pranic Healing USA, pp. 14-17.

14. Saigal S, Rosenbaum P, Stoskopf B, Hoult L, Furlong W, et al. (2005). Development, reliability and validity of a new measure of overall health for pre-school children. Qual Life Res 14(1): 243-257.

15. Radhakrishna S (2010) Application of integrated yoga therapy to increase imitation skills in children with autism spectrum disorder. Int J Yoga 3(1): 26-30.

16. Stone W, Ruble L, Coonrod E, Hepburn S, Pennington M, et al. (2010) Treatment and research institute for autism spectrum disorders social skills assessment manual. Vanderbilt Kennedy Center, Nashville, TN, USA.

17. Cheng M (2011) Ottowa mood scales.

18. Lincoln Y, Guba E (1985) Naturalistic inquiry. Sage, Beverly Hills, CA USA

19. Miles M, Huberman A (1994) Qualitative data analysis: an expanded source book. ( $2^{\text {nd }}$ edn), Sage, Thousand Oaks, CA, USA.

20. Patton MQ (2002) Qualitative evaluation and research methods. (3 $3^{\text {rd }}$ edn), Sage, Thousand Oaks, CA, USA.

21. Kirk M, Boon B, DiTuro D (2006) Hatha yoga illustrated, Human Kinetics, Champaign, IL, USA.

22. Radhakrishna S, Nagarathna R, Nagendra H (2010) Integrated approach to yoga therapy and autism spectrum disorders. J Ayurveda Integr Med 1(2): 120-124.

23. Crane C, Reynolds J (2004) The Source Book ( $3^{\text {rd }}$ edn), Crane/Reynolds Inc, Houston, USA.

\section{Your next submission with Juniper Publishers} will reach you the below assets

- Quality Editorial service

- Swift Peer Review

- Reprints availability

- E-prints Service

- Manuscript Podcast for convenient understanding

- Global attainment for your research

- Manuscript accessibility in different formats

( Pdf, E-pub, Full Text, Audio)

- Unceasing customer service

ack the below URL for one-step submission

https://juniperpublishers.com/online-submission.php 